Journal of Extension Education

Vol. 28 No. 1, 2016

\title{
Social Capital Formation through Farm Women Groups in Vegetable Production in Kollam District of Kerala
}

\author{
Revathy Chandran ${ }^{1}$ and G.S. Sreedaya ${ }^{2}$
}

\begin{abstract}
Social capital refers to the trust, mutual understanding and shared values which facilitate the collective action and social co-ordination. It can create a service which can enhance the output obtainable from other inputs. Trust, co-operation, networks and norms are the important aspects of social capital. Farmer producer organization is the most appropriate institutional form around which to mobilize farmers and build their capacity to collectively leverage their production and marketing strength. Women groups have emerged as a major source of inspiration for women and collective action of women through their groups strengthened women in all spheres of life. This study was conducted among 120 women respondents in six selected panchayats of Kollam district in Kerala with the he main objective of assessing the social capital formation through farm women groups. Social Capital was measured using Social Capital Assessment Tool (SOCAT) developed by World Bank. The results showed that there $82 \%$ of the respondents had medium level of social capital formation and the continuous efforts of various governmental and non-governmental agencies had tremendously helped in shifting this neutral attitude of people.
\end{abstract}

Keywords : Social capital, social networks, trust, women groups.

\section{INTRODUCTION}

Social capital refers to the trust, mutual understanding and shared values which facilitate the collective action and social co-ordination. Social capital ponders to the characteristics of a society that stimulates co-operation among the individuals. It can create a service which can enhance the output obtainable from other inputs. 'Networks', 'norms' and 'trust' can be considered as the three important attributes of Social capital.
Unlike human and physical capital, social capital lies as a latent (embedded) resource waiting to be mobilised and utilised, growing and developing with use. (Morris et al.,2006) .

Women groups is the new strategy which enables women to achieve their needs through the overall output of the group. This expected collective or economic benefits derived from the preferential treatment and cooperation between individuals and groups is known

1-Senior PG scholar and 2- Assistant Professor, Department of Agricultural Extension, College of Agriculture, Kerala Agricultural University, Vellayani-695522, Thiruvananthapuram,Kerala. 
as the social capital. Social capital is enhanced through people employing both functioning and capabilities in Self help groups within a framework of trust and inclusion, resulting in closer bonding and reciprocal arrangements that bring benefits to all members (Ibrahim ,2006). Kerala is a consumer state as far as vegetables are concerned. Major share of the fresh vegetable supply for the state comes from neighbouring states. Women groups have emerged as a major source of inspiration for women. Groups provide a platform for women through which they can speak for their needs and work for their needs. With this background, the present study aims at measuring the scale of social capital formation through farm women groups and to study the involvement of farm women in panning production and marketing aspects of vegetables.

\section{METHODOLOGY}

The scale of Social Capital was measured using Social Capital Assessment Tool (SOCAT) developed by (World Bank, 2010). The SOCAT is a multifaceted instrument designed to collect social capital data at the house hold, community and organisational levels. It includes both qualitative and quantitative measurement techniques. Qualitative techniques include Focus Group Discussion (FGD), Community Mapping and Participatory Rural Appraisal (PRA). The quantitative techniques involved the use of pre-tested and structured interview schedules.

SOCAT seeks to operationalize emerging theories regarding the dimensions of social capital, creating validated indicators that can measure the levels of social capital and its relationship with other development indicators in the area of poverty alleviation. Six panchayats were identified from Kollam district based on the number of maximum women groups and one group was selected by random sampling. Fifteen members were randomly selected from each group along with 30 extension facilitators of Kollam district which constitute a total of 120 respondents.

\section{FINGINGS AND DISCUSSION}

\section{Social capital measured using SOCAT}

- Due to exposure to the group meetings respondents was well aware of their resources, institutions and marketing channels both within and outside the Panchayat.

- All the respondents were aware of the support services received from VFPCK, KUDUMBASHREE, KRISHI $B H A V A N$ and they frequently visit these organizations.

- Membership in the group enhanced individual soft skills like communication skill, leadership, team building, conflict management etc of the respondents.

- Group meetings enhanced connection, co-ordination and co- 
operation among individuals.

- Also, exposure to the trainings and acquaintance with staff of various organizations helped the respondents to improve their evaluation ability.

- Members also exhibited improved risk taking ability because of the feeling of 'togetherness'.

- Enhanced trust, bonding and reciprocal arrangements among group members created more socialization even between the family members of the respondents.

\section{Distribution of Respondents Based on the Scale of Social Capital Formation.}

It was found that majority of respondents belongs to the medium category in their social capital formation. i.e. 82 percent of the respondents belong to the medium category whereas only 10 per cent belongs to the high category. Eight per cent of the respondents fall under the low social capital formation groups. Majority of the people in the society have a neutral attitude towards co-operation, helping others and volunteership. It is obvious that continuous efforts of State department of agriculture, VFPCK, Kudumbasree Mission and other NGOs, have created a wave in farming community especially vegetable scenario. A lot of groups were promoted by these organization many of them are women group and this might be the reason as majority of the respondents fall under medium category and for a considerable reduction of respondents who fall in the low category. (Fig.1)

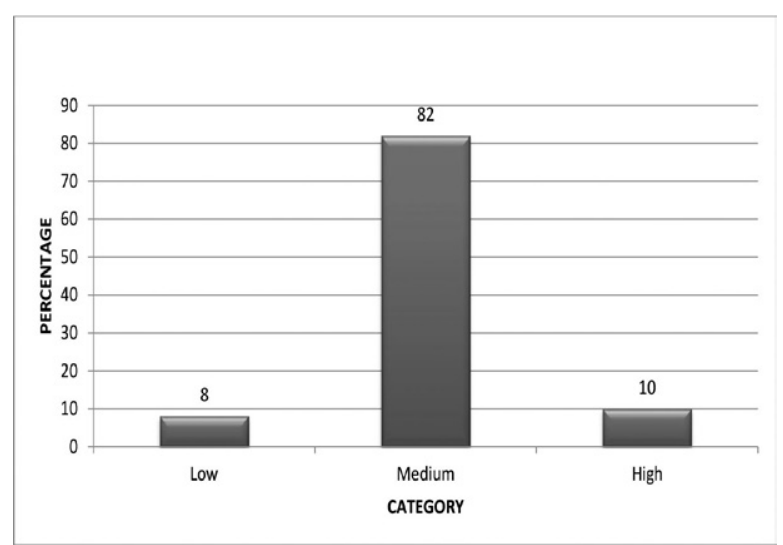

Fig 1. Distribution of Respondents based on the Scale of Social Capital Formation.

\section{Scale of Social Capital Formation}

The maximum social capital was observed in the Karavaloor panchayat with $71 \%$, followed by Pavithreshwaram and the minimum social capital was obtained in Pooyapally panchayat securing $48 \%$.

$$
(n=90)
$$

From the Participating Rural Appraisal conducted and discussions with the women groups, it was evident that there was good social capital formation among the members of the group under study. Karavaloor panchayat where the maximum social capital formation was achieved have very active women members who are looking forward for more opportunities. The activities of kudumbasree over the last few years might have increased the level of trust and solidarity among the group members 


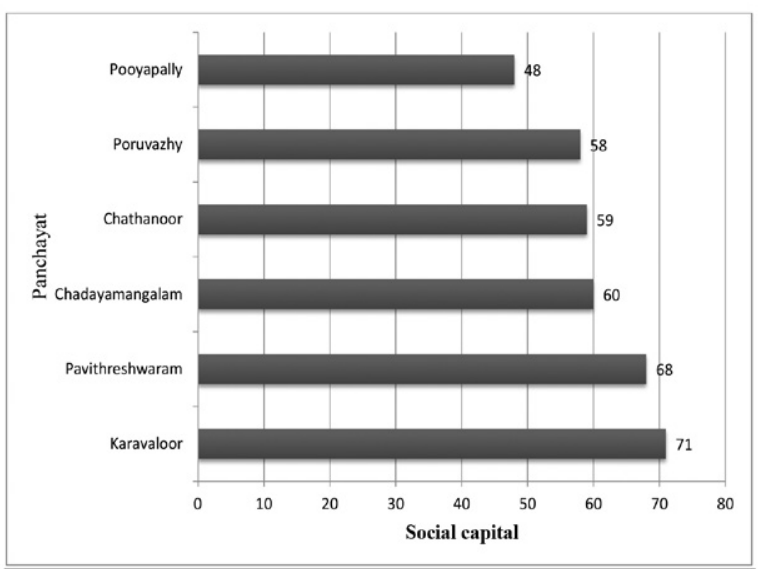

Fig 2. Distribution of Respondents based on the Scale of Social Capital Formation.

in Karavaloor panchayath. This might be the reason for high social capital in Karavaloor PanchayatKudumbashree, ATMA and VFPCK have enabled women to organize into groups and thereby increase their social capital formation through interaction, entrepreneurship and creative activities as well.

\section{CONCLUSION}

This study is significant as it addresses the soccial capital formation through farm women groups. The present study revealed that majority of the farm women had medium level of social capital formation $(82 \%)$. It was found that the maximum social capital formation was observed in Karavaloor panchayat with $71 \%$ social capital formation followed by Pavithreshwaram with $68 \%$ social capital formation. The study revealed that more support from the government and extension facilitators is needed for developing a high level of social capital formation.

\section{REFERENCES}

Ibrahim, S. (2006), From Individual to Collective Capabilities: The Capability Approach as a Conceptual frame work for self help. Journal of Human Development. 7(3), 397-416.

Morris, S., Woodworth, W. \& Hiatt, S. (2006). The value of networks in enterprise development: Case studies in Eastern Europe and Southeast Asia. Journal of Developmental Entrepreneurship. 11(4), 345-356.

Sanyal, P. (2009). From credit to collective action: The role of microfinance in promoting Women's social capital and normative influence. American Sociological Review. 74: 529-550.

World Bank. (2009). World Development Report 2007/2008. World Bank, Washington. 